\title{
A new method for the determination of at-sea activity in sea turtles
}

\author{
Sandra Hochscheid*, Rory P. Wilson \\ Institut für Meereskunde, Düsternbrooker Weg 20, D-24105 Kiel, Germany
}

\begin{abstract}
Interpretation of diving profiles of aquatic animals would be considerably enhanced by additional behavioural information. A new sensor is presented here which records animal movements. This sensor was tested on a captive loggerhead turtle Caretta caretta which showed similar activity patterns to free-living green turtles Chelonia mydas. A computer program with user-selectable options was developed to analyse the data consistently and rapidly. Using our sensor we calculated the total resting time, which differed by less than $5 \%$ from the real resting time when the sampling interval was $2 \mathrm{~s}$. The method was additionally tested for difterent sampling intervals to find out its applicability for field studies.
\end{abstract}

KEY WORDS: Activity sensor - Sea turtles - At-sea activity . Dive profiles - 3-D compass

The activity and diving behaviour of marine airbreathing animals is logistically difficult to study. This is especially true for sea turtles, which spend most of their life submerged. However, recent technological advances in animal-carried units has led to new insights into the remarkable diving capacity of these marine reptiles. Typically, the use of data-logging devices such as TDRs (time depth recorders) provides information from which dive profiles (the graphic representation of depth as a function of time) can be determined (for example Eckert et al. [1989] for leatherback turtles Dermochelys coriacea, Sakamoto et al. [1990] for loggerhead turtles Caretta caretta, Van Dam \& Diez [1996] for hawksbill turtles Eretmochelys imbricata, and Rice et al. [in press] for green turtles Chelonia mydas). However, in the absence of other data, the function of these various dive patterns

\footnotetext{
- Present address: Department of Zoology, University of Aberdeen, Tillydrone Avenue, Aberdeen AB24 2TZ, Scotland, UK E-mail: s.hochscheid@abdn.ac.uk
}

is speculative. For example Van Dam \& Diez (1996) defined 2 dive types as 'foraging dives' and 'resting dives' uniquely based on the different shapes in the depth/time-diagram. Wilson \& Wilson (1995), however, have shown that for diving birds even limited extra information on animal behaviour during diving can enhance the reliability of determined dive patterns. In this work we present a new sensor which can function as an activity sensor integrated into a recording unit for deployment on air-breathing marine animals.

A rare earth magnet (Vacodym 335, Vacuumschmelze, Hanau, Germany) in the form of a bar (dimensions $7 \times 2 \times 2 \mathrm{~mm}$ ) and magnetised along its long axis was placed inside a hollow plastic sphere (external diameter $10 \mathrm{~mm}$, wall thickness $=0.5 \mathrm{~mm}$ ) so that the 2 ends were diametrically opposite at the sphere's equator. A small lead weight was placed directly beneath the magnet and stuck to the inside wall of the sphere so that when the sealed sphere was placed in silicon oil the long axis of the magnet was parallel to the earth's surface, being held in this position by the lead weight at the bottom of the sphere. When in this position, the magnet responded to the earth's magnetic field by aligning itself so that its long axis ran north-south, thus acting as a compass. The sphere was placed inside a larger, hollow plastic sphere (external diameter $14 \mathrm{~mm}$, wall thickness $1 \mathrm{~mm}$ ) which was filled with silicon oil and sealed. Subsequently, 2 Hall sensors (which produce a voltage as a function of magnetic field strength) were both placed at the equator of the larger sphere but at an angle of $90^{\circ}$ with respect to each other. This unit functions as both a 3-D compass and an activity sensor (Fig. 1).

When this unit is mounted in a recording unit on an animal, changes in the animal orientation result in a change in the position of the internal sphere with respect to the external sphere. The position of the internal sphere is determined by the horizontal component of the earth's magnetic field, the position of the 


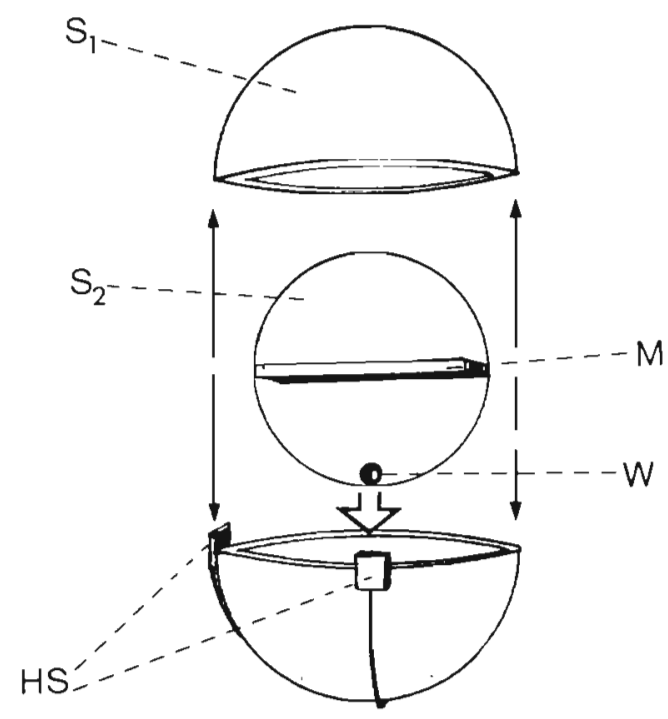

Fig. 1. The 3-D compass system. Sphere $\mathrm{S}_{2}$ was air filled while $S_{1}$ was filled with silicon oil and sealed before being installed in the recording logger. $M=$ magnet, $W=$ lead weight HS = Hall sensors activities and movements of free-living animals, our captive specimen was able to swim continuously in circles, or rest, or move slowly along the front window of the tank so that the response of the compass with respect to these activities could be examined.

Data were accessed via an interface RS 232 and read out directly following the experiment. Visual examination of the voltage values derived from the Hall sensors showed a clear relationship between animal activity and change in voltage over time (Fig. 2). For potential consideration of animal activities in the field it was necessary, however, to be able to quantify the data mathematically. Although a number of different options were attempted, the simplest and most useful proved to be consideration of the standard deviation (SD) (Zar 1984) of the voltage over a specified time period. The form taken by the SD was, however, somewhat modified to enhance its descriptive power. Specifically, 3 parameters were taken into account:

(1) The number of values for which the SD had to be calculated $(N)_{i}$

(2) The minimal voltage difference between adjacent values which had to occur before the difference was external sphere is determined by the animal. The relative position of the 2 spheres is given by the relative voltages of the 2 Hall sensors. The changes in the voltage produced by the Hall sensors can also be used as an indication of activity since changes in activity produce changes in body orientation.

The form that these changes in voltage take was examined on a captive adult loggerhead turtle Caretta caretta at the Stralsund aquarium (Germany). The recording unit was a DK600 data-logger (Driesen \& Kern GmbH, Bad Bramstedt, Germany, $2 \mathrm{MB}$ flash RAM, 16 bit resolution for each of a total of 6 channels, 2 of which were dedicated to the Hall sensors in the compass) which was attached using velcro glued to both the underside of the data-logger and the carapace of the turtle (third right lateral scute). In addition to the readings of the 2 Hall sensors the DK600 recorded, among other things, absolute pressure via an integrated depth gauge (resolution better than $0.1 \mathrm{~m}$ ). Immediately after attachment the animal was released in the tank (length $4 \mathrm{~m}$ $\times$ width $3.5 \mathrm{~m} \times$ depth $2.2 \mathrm{~m}$ ) and observed for the following $3 \mathrm{~h}$. Every change in turtle activity was noted to the nearest second using a digital watch. The sampling interval of the data-logger was set at 2 s. Although turtles so confined clearly cannot exhibit all

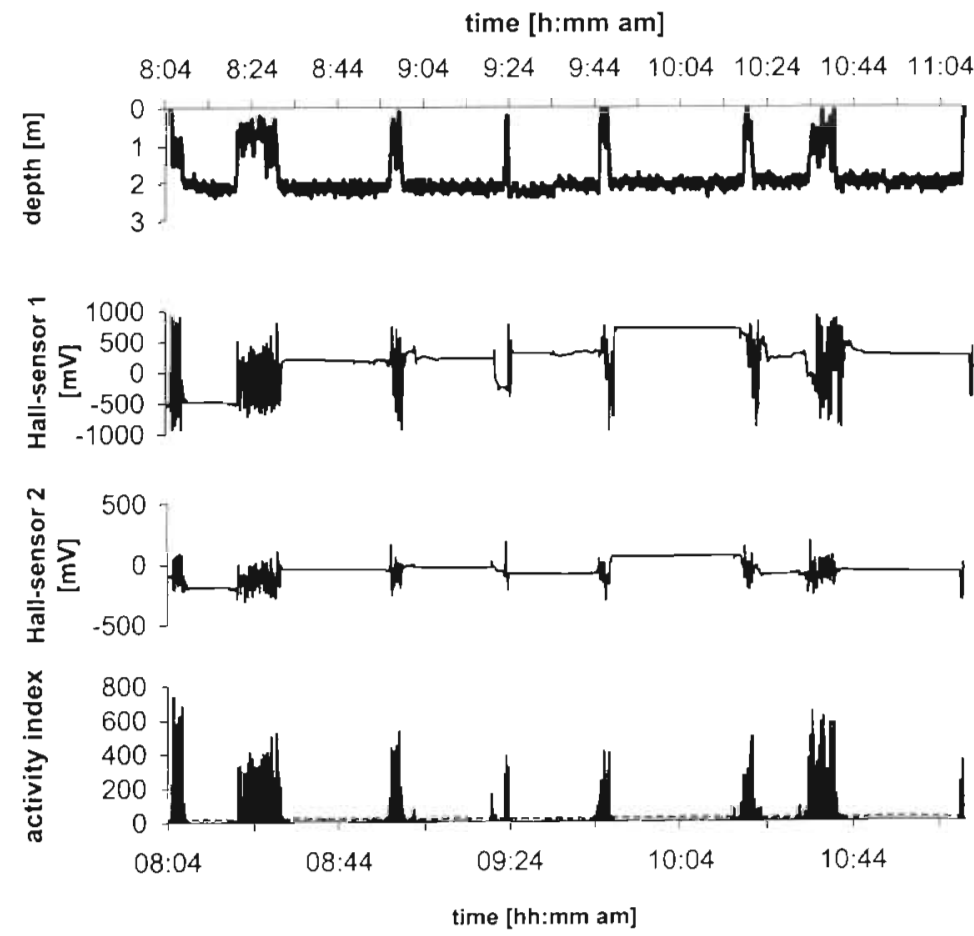

Fig. 2. Diving pattern of a captive loggerhead turtle (top) and the simultaneous recordings of the activity sensor (2 graphs in the middle). Where there was no change in voltage in either one of the Hall sensors the turtle was resting, while high voltage changes are due to swimming (at ca 08:34 $\mathrm{h}$ and at ca 10:34 h) and surfacing activities. These changes are mirrored by the graph of the activity index (bottom). which was derived from Hall sensor $1(N=3, D=0)$. Values below the threshold for resting (dashed line) are due to resting phases 
considered valid $\left(V_{\mathrm{d}}\right)$. This proved necessary because different Hall sensors had different baseline noise levels (usually between 0.5 and $8 \mathrm{mV}$ ) so that even a completely stationary logging unit exhibits apparent (minimal) movement; and

(3) The number of times that the voltage could exceed a certain value within a series $N$ under consideration before the SD was actually calculated $(D)$. This factor was added because when the turtle was resting underwater it occasionally changed position without otherwise apparently waking up, a procedure which could lead to massive increases in SD even though the major activity of the animal had not changed.

The calculation of the modified SD was put into a program (Activ2.0 Jensen Software Systems, Laboe, Germany) which could be run using the same data set with different values for $N$ and $D$ to see how variation in these values affected determined activities. In addition, the rate at which animal orientation was logged was changed in the recorded data by selectively deleting data so as to simulate recording intervals of 4,8 and $16 \mathrm{~s}$, in addition to the $2 \mathrm{~s}$ interval used for the experiment.

The observations showed that the loggerhead turtle mainly rested on the bottom, for a total of $155 \mathrm{~min}$ $(83.3 \%$ of total time). This time was accumulated in 7 successive phases which had a mean duration of $22 \mathrm{~min}$ (range $=12$ to $29 \mathrm{~min}$ ). Between these phases the turtle ascended to breathe 1 to 3 times at the surface, events which were sometimes followed by a short period swimming near the water surface (at e.g. ca 08:24 $\mathrm{h}$ and at ca 10:34 h) before the animal descended to rest again.

For the activity calculation $N$ was chosen to be $3,6,8$ or 10 , whereas $D$ was set at 2 for $N=8$ or 10 , at 1 for $N=6$ and at zero for $N=3$. The resulting activity index (AI) was at a maximum when the turtle was swimming (typical values ranged between 68 and $100 \%$ of maximum encountered SDs, the precise value being dependent on differences in sampling interval and $N$ ). In contrast, the AI of the resting phases was extremely low (between 1.4 and $2.0 \%$ of maximum encountered SDs). The threshold for resting was therefore taken to be ca $2 \%$ of the maximum AI (Fig. 2). By summing all AI values below this $2 \%$ threshold it was possible to calculate the total resting time of the turtle and compare it to the real resting time (Fig. 3). No clear differentiation could be made between different swimming activities (e.g. whether the turtle was swimming in circles or whether it was moving to and fro at the front window).

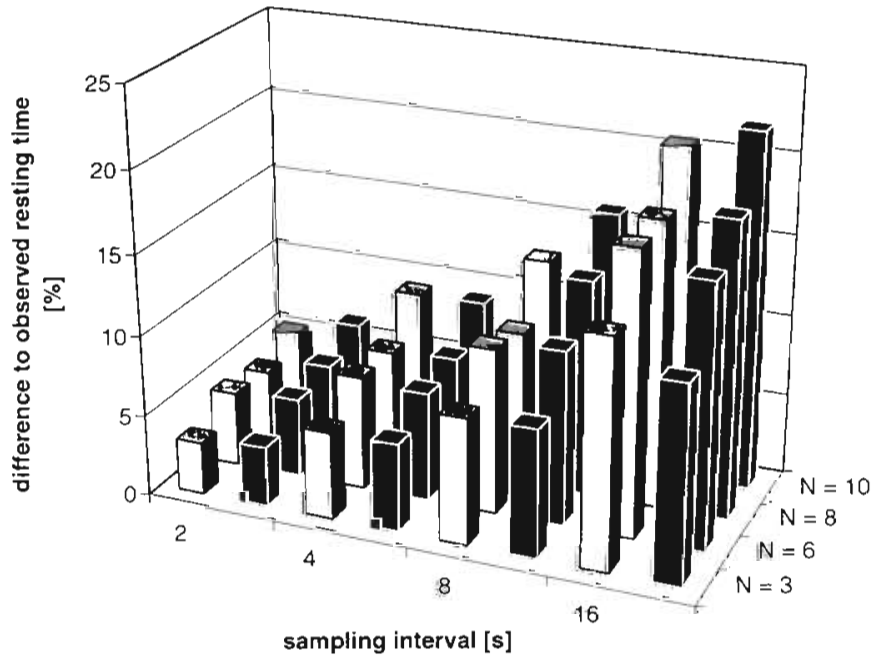

Fig. 3. The difference between the observed resting time of a captive loggerhead turtle and the calculated resting time as a function of the sampling interval and $N$ (for explanations see text). The white columns represent Hall sensor 1 and the black columns represent Hall sensor 2

Small values for $N$ gave the best index of real activity because they allowed for the finest temporal resolution. In addition, where SD was calculated from $N$ which spanned 2 different activities, a composite SD was obtained with a value somewhere between activity $\mathrm{A}$ and activity $\mathrm{B}$. This would tend to blur the definition of activities from field studies and make Als characteristic of particular behaviours less readily definable. The likelihood that this will occur is directly

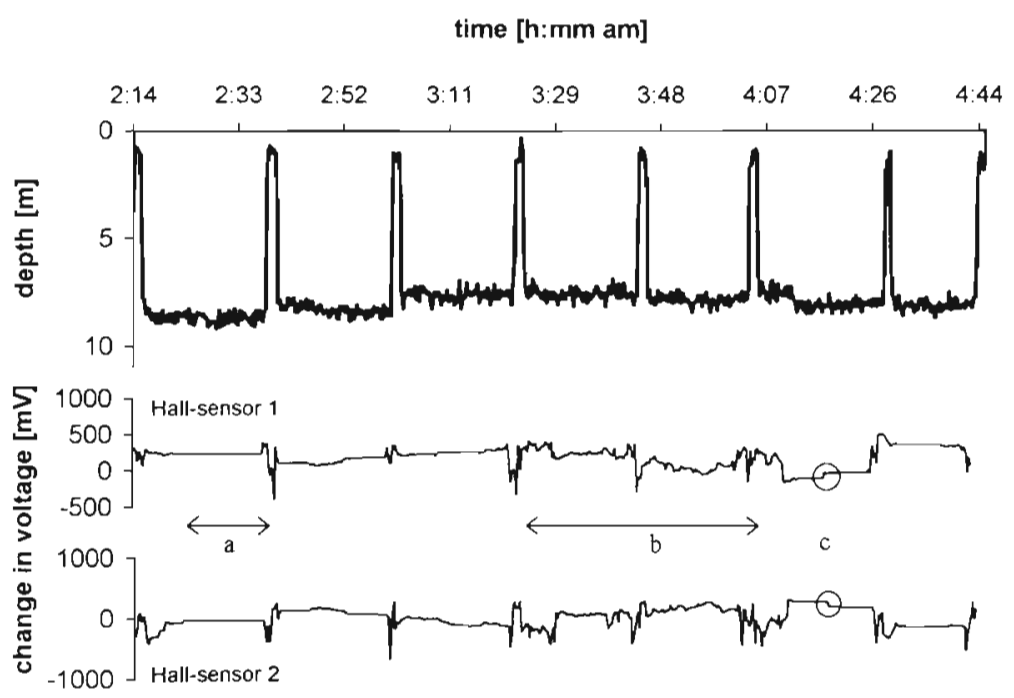

Fig. 4. The data from both Hall sensors ( 2 bottom graphs) show the state of movement of a free-living green turtle during a series of u-dives (top, Hochscheid 1998). (a) Resting and (b) activity (moving about on the sea bed) can be clearly distinguished (cf. Fig. 2) as can (c) a change in the animal's position during a resting phase 
dependent on the size of $N$ and the rate at which behaviours change. Martin \& Bateson (1986) state that in order to detect the occurrence of a particular type of behaviour, the interval at which sampling should take place should be of the order of half the length of time that the behaviour takes to be executed. This rule is complicated by the process of behaviour determination via multiple samples as suggested here. A potential solution is to reduce sample interval to a minimum, which allows the time span over which $N$ occurs to be minimised. In practice, however, the rate at which data are accumulated is, in part, limited by the memory size of the logger.

When the DK600 data-logger is used in field studies its data reveal a strong similarity between the diving pattern presented in Fig. 2 and those of free-living turtles. U-dives (where the animal descends rapidly to a specific depth where it spends extended time before returning to the surface, sensu Le Boeuf et al. 1988), for example, show a variety of different apparent activities as it can be seen from the voltage changes of the Hall sensors (Fig. 4). The program for activity calculation can be run on these data for activity determination, in particular dive patterns (Hochscheid et al. 1999, in this issue).

It would be beneficial if this method for activity determination were further developed so that a distinction between different swimming activities could be made. It may be possible, for example, to define more thresholds between particular activity levels such as foraging and travelling. The confined conditions on captive turtles made this exercise difficult for us. Furthermore, we would suggest that, although the presented method is well-suited for the elucidation of resting phases in sea turtles, it could be applied to other aquatic as well as terrestrial animals in order to elucidate activity.

Acknowledgements. This work was made possible using equipment made available by the Deutsche Forschungs-

Editonal responsibility: Otto Kinne (Editor),

Oldendorf/Luhe, Germany gemeinschaft. The magnets of the compass system were kindly provided by Mr Reisert. Vacuumschmelze, Hanau. We are grateful to Dieter Adelung for financial support and to Sandra Storch, Harald Benke, Klaus Hader, $\mathrm{Mr}$ Tschiesche and the staff of the Stralsund aquarium for their help during the experiment. We are indebted to Jochim Lage for developing the computer software and would like to thank Stefan Garthe. Gerrit Peters and David Grémillet for helpful advice.

\section{LITERATURE CITED}

Eckert SA, Eckert KL, Ponganis P, Kooyman GL (1989) Diving and foraging behavior of leatherback sea turtles (Dermochelys coriacea). Can J Zool 67:2834-2840

Hochscheid S (1998) Das Tauchverhalten von Chelonia mydas vor Zypern. MSc thesis, University of Kiel

Hochscheid S, Godley BJ, Broderick AC, Wilson RP (1999) Reptilian diving: highly variable dive patterns in the green turtle Chelonia mydas. Mar Ecol Prog Ser 185:101-112

Le Boeuf BJ, Costa DP, Huntley AC, Feldkamp SD (1988) Continuous, deep diving in female northern elephant seals, Mirounga angustirostris. Can J Zool 66:446-458

Martin P, Bateson P (1986) Measuring behaviour. Cambridge University Press, Cambridge

Rice $M R$, Balazs $G H_{1}$ Hallacher L, Dudley W, Watson G, Krusell $K$, Larson B (in press) Diving, basking and foraging patterns of a sub-adult green turtle at Punalu'u, Hawaii. In: Proceedings of the 18th Symposium on Sea Turtle Biology and Conservation, 3-7 March 1998, Mazatlán, Mexico

Sakamoto W, Naito Y, Uchida I, Kureha K (1990) Circadian rhythm on diving motion of the Loggerhead Turtle Caretta caretta during inter-nesting and its fluctuations induced by the oceanic environmental events. Nippon Suisan Gakkaishi 56(2):263-272

Van Dam RP, Diaz CE (1996) Diving behavior of immature hawksbills (Eretmochely imbricata) in a Caribbean cliffwall habitat. Mar Biol 127:171-178

Wilson RP, Wilson MPT (1995) The foraging behaviour of the African Penguin Spheniscus demersus. In: Dann P, Norman I, Reilly $\mathrm{P}$ (eds) The penguins: ecology and management. Surrey Beatty \& Sons Pty Limited, Chipping Norton, p 244-265

Zar JH (1984) Biostatistical Analysis. Prentice-Hall, Englewood Cliffs, $\mathrm{NJ}$

Submitted: November 25, 1998; Accepted: March 29, 1999 Proofs received from author(s): May 27, 1999 